\title{
Correlation between Self-Reported Daily Activity and Submaximal Walk Test in the Assessment of Functional Capacity among Patients with Hypertension
}

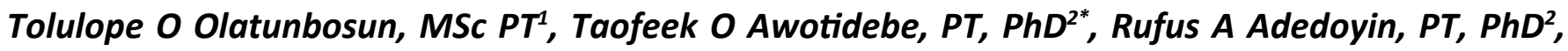 \\ Olufesola M Fasakin, RN, MSc ${ }^{3}$, Suraj A Ogunyemi, MBChB, FWACP ${ }^{4,5}$, Abayomi A Olawoye, PT, DPT \\ and Adekola J Odunlade, MSc, PT $^{1}$
}

\begin{abstract}
${ }^{1}$ Physiotherapy Unit, Department of Medical Rehabilitation, Obafemi Awolowo University Teaching Hospitals Complex, Nigeria ${ }^{2}$ Department of Medical Rehabilitation, College of Health Sciences, Obafemi Awolowo University, Nigeria

${ }^{3}$ Nursing Services Department, Veterans Affairs Medical Center, USA

${ }^{4}$ Cardiac Care Unit, Obafemi Awolowo University Teaching Hospitals Complex, Nigeria

${ }^{5}$ Department of Medicine, College of Health Sciences, Obafemi Awolowo University, Nigeria

${ }^{6}$ Department of Physical Therapy, Five Towns Premier Nursing and Rehabilitation Center, USA

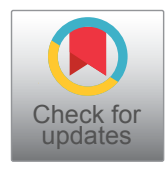

*Corresponding author: Taofeek O Awotidebe, PhD, PT, Department of Medical Rehabilitation, College of Health Sciences, Obafemi Awolowo University, Ile-Ife, Nigeria, Tel: +2348037196021; +2348188981415
\end{abstract}

\begin{abstract}
Background: Time constraint on the part of clinicians or musculoskeletal comorbidities in the lower limbs in some patients with hypertension may sometimes prevent submaximal walk test. Hence, self-reported activity thus becomes an alternative method for assessing quick functional capacity (FC). This study assessed FC using a self-reported daily activity tool; Duke Activity Status Index (DASI) and correlated its value with 6-Minute Treadmill Walk (6-MTW) among patients with hypertension.

Methods: This cross-sectional study recruited 150 (males: $\mathrm{n}=54$; females: $\mathrm{n}=96$ ) patients with mild-to-moderate hypertension from the Cardiac Care Unit of a Nigerian teaching hospital using purposive sampling technique. Physical and socio-demographic characteristics were recorded. Pre and post 6-MTW cardiovascular parameters were measured using an electronic sphygmomanometer. FC: maximum oxygen consumption (VO2 max) was evaluated using DASI and 6-MTW. Data were analyzed using descriptive and inferential statistics. Alpha level was set at $p<0.05$
\end{abstract}

Results: Participants were comparable in all physical and cardiovascular variables except body mass index (BMI) and heart rate $(p<0.05)$. The means of estimated VO2 max by DASI and 6-MTW were $24.4 \pm 5.7$ and $12.5 \pm 3.6 \mathrm{~mL} / \mathrm{kg} / \mathrm{min}$ respectively. There was significant moderate correlation between DASI and 6MTW estimated VO2 $\max (r=0.58 ; p=$ $0.001)$. However, there were significant inverse correlations between estimated DASI VO2 max and each of age ( $r=$ $-0.39 ; p=0.006)$ and BMI $(r=-0.35 ; p=0.012)$. Similarly, there were significant inverse correlations between estimated 6-MTW VO2 max and each of age $(r=-0.38 ; p=$ $0.012)$ and BMI ( $r=-0.29 ; p=0.043)$.

Conclusion: Estimated functional capacity assessed using the self-reported daily activity (DASI) demonstrated significant positive correlation with six-minute treadmill walk in patients with hypertension. DASI may be used as a quick tool for assessing functional capacity in patients with hypertension. Findings from this study may help to limit problems of insufficient laboratory facilities and inadequate experts in the assessment of functional capacity in many patients with cardiac challenges.

\section{Keywords}

Self-reported activity, Functional capacity, Submaximal walk test, Hypertension

Citation: Olatunbosun TO, Awotidebe TO, Adedoyin RA, Fasakin OM, Ogunyemi SA, et al. (2021) Correlation between Self-Reported Daily Activity and Submaximal Walk Test in the Assessment of Functional Capacity among Patients with Hypertension. Int J Clin Cardiol 8:238. doi.org/10.23937/23782951/1410238

Accepted: September 11, 2021: Published: September 13, 2021

Copyright: (c) 2021 Olatunbosun TO, et al. This is an open-access article distributed under the terms of the Creative Commons Attribution License, which permits unrestricted use, distribution, and reproduction in any medium, provided the original author and source are credited. 


\section{Abbreviations}

FC: Functional Capacity; $\mathrm{VO}_{2}$ max: Maximum Oxygen Consumption; DASI: Duke Activity Status Index; 6-MTW 6-Minute Treadmill Walk; BMI: Body Mass Index; CCU: Cardiac Care Unit; OAUTHC: Obafemi Awolowo University Teaching Hospitals Complex; CVD: Cardiovascular Disease; SBP: Systolic Blood Pressure; DBP: Diastolic Blood Pressure; RPP: Rate Pressure Product

\section{Introduction}

Cardiovascular disease (CVD) is one of the leading causes of morbidity and mortality worldwide with hypertension as the principal risk factor for all major CVDs $[1,2]$. Hypertension is a serious global public health problem affecting approximately one billion people globally and more than three million people die annually as a direct result of the condition especially in low and middle income countries [3]. In sub-Sahara Africa, there is substantial evidence that hypertension has become an important public health issue for which an enduring treatment is of utmost importance [24]. To a large extent, pharmacological treatment of hypertension has contributed to appreciable blood pressure control, delay in target organ damage and lowers CVD events [4]. However, socio-economic problem, drug adherence, cost of medication and adverse effects of drug are significant limiting factors for achieving successful hypertension control $[4,5]$. Thus, many health authorities have advocated the incorporation of lifestyle approaches including dietary modification, weight control and exercise in the management of hypertension $[5,6]$.

Exercise as a non-pharmacological approach has been reported to lower blood pressure, improve functional capacity, quality of life and significant reduction in the CVD risk if implemented effectively $[7,8]$. However, baseline functional capacity of an individual needing exercise is required in order to stratify CVD risk, implementation of an effective exercise prescription and enrollment. Numerous investigations have demonstrated that assessment of functional capacity provides important diagnostic and prognostic information in a wide variety of clinical and research settings [9]. Presently, the current gold standard for assessing a person's aerobic exercise response is the maximum incremental cardiopulmonary exercise test using protocols such as Bruce or modified Bruce protocol [10]. However, availability of equipment and experts in this field are limited in many low and middle income nations [11]. Furthermore, most daily activities are performed at submaximal levels of exertion and, therefore, it has been proposed that submaximal functional tests are a better reflection of physical capability [12].

Popular amongst submaximal functional tests are two, six or twelve-minute walk tests and incremental shuttle walk test $[13,14]$. Owing to the importance of functional capacity assessment in the management of patients with CVD, the 6-minute walk test (6-MWT) has been reported to be important in the objective evaluation of functional capacity in cardiopulmonary rehabilitation $[13,15]$. Studies on functional walk tests concluded that the 6-MWT is easy to administer, better tolerated, and more reflective of activities of daily living than other walk tests $[11,15]$. However, presence of comorbidities such as musculoskeletal disorders including hip or knee arthritis and low-back pain, higher risk of falling, and time constraint among clinicians might hinder use of submaximal walk test for the assessment of functional capacity. Hence, the use of self-reported activity thus becomes an alternative choice for assessing functional capacity.

Several self-administered and interview-based activity questionnaires have been developed to estimate a patient's functional capacity $[16,17]$. The Duke Activity Status Index (DASI) is a self-reported measure of ability to do twelve personal, household and recreational activities used to assess cardiovascular capacity $[17,18]$. It has been reported that the DASI has high criterion validity and its predictive significance and simplicity recommends it over several other selfadministered tools for evaluating functional capacity [19]. Previous researches seldom compared the DASI with established functional exercise capacity tests to determine whether its predictive capacity is as strong as those of submaximal exercise tests. Furthermore, there is dearth of empirical data on the assessment of functional capacity among patients with hypertension using self-reported tool such as DASI. This study was designed to assess and correlate the DASI's functional capacity outcomes with that of submaximal walk test among patients with hypertension.

\section{Methods}

\section{Study sample}

This was a cross-sectional study design involving patients with mild to moderate hypertension who were receiving medical treatment at the Medical Outpatient Department; Cardiac Care Unit, Obafemi Awolowo University Teaching Hospitals Complex (OAUTHC), lleIfe, Nigeria. Participants were recruited into the study using purposive sampling technique. The purpose of the study was explained to participants and those who volunteered to participate signed an informed consent before participation. The study protocol was approved by the Ethics and Research Committee of OAUTHC lle - Ife, Nigeria. The study was conducted at the Physiotherapy Department of OAUTHC, Ile-Ife, Nigeria.

\section{Inclusion criteria}

Eligibility for inclusion were:

i. Clinical diagnosis of mild to moderate 
hypertension ( $\geq 140 / 90 \leq 180 / 109 \mathrm{mmHg}$ ), regular use of prescribed anti-hypertensive medications.

ii. Participants whose ages were 40 and 65 years.

iii. Capability to perform submaximal walk test.

\section{Exclusion criteria}

They were excluded from the study if presented with

i. History of severe hypertension, unstable angina, congestive heart failure or other severe cardiac disease,

ii. Visual impairment and inability to ambulate without support.

The minimum sample size for the study was calculated using the formula: $n=Z^{2}(p(1-p) / e 2$ where, $\mathrm{n}=$ required sample size, $\mathrm{Z}=\mathrm{z}$-value $(\mathrm{z}$-value for $95 \%$ confidence level (1.96), $p=$ The estimated proportion of an attribute present in the population, and $\mathrm{e}=$ The desired level of precision (i.e. confidence interval, expressed as decimal (0.05) [20]. Taking the overall prevalence (p) of hypertension in Nigeria using the $160 / 95 \mathrm{mmHg}$ cut-off point, the prevalence is about $11.2 \%$ [21] and a sample size of 142 was estimated. However, the sample size was increased to 150 participants to accommodate for possible missing data.

\section{Procedure}

The purpose of the study was explained to the participants before obtaining an informed consent. Thereafter, socio-demographic and physical characteristics were assessed using standard procedures while cardiovascular parameters including heart rate, systolic and diastolic blood pressure were assessed using an electronic sphygmomanometer (Omron Intelli sense M6 Comfort, Japan). The Duke Activity Status Index (DASI) was administered to each participant to assess functional capacity (maximum oxygen consumption $\left[\mathrm{VO}_{2}\right.$ max]) based on individual's daily activity. Thereafter, participant underwent a six minute submaximal walk test on a treadmill device (Enraf Nonius, Treadmill manufactured by Bonte Technology BV, Netherlands) as described by Stevens, et al. [22].

Assessment of functional capacity: The Duke Activity Status Index (DASI) is a self-reported measure of ability to perform 12 items daily activities including personal care, household task, sexual function, and recreational activities [17]. Each was assigned a metabolic equivalent (MET) used to assess functional capacity. The DASI required participant to tick either a "yes" or "no" to each question. The sum of "yes" responses were multiplied by 0.43 and then add 9.6 to arrive at DASI score to give the estimated maximum oxygen consumption ( $\left.\mathrm{VO}_{2} \mathrm{max}\right)$. The final score ranges between 0 and 58.2 points. The higher the scores, the better the functional capacity scores [17]. Each participant was given the questionnaire to respond to the 12 items which was completed within three to five minutes. The total score was determined and recorded for each participant. Earlier, the psychometric properties of the instrument was determined by translating the original DASI to Yoruba language and back translated to English language by experts. The translation was done by Yoruba language experts while back translation was done by English experts from the Department of linguistics and African languages studies of the Obafemi Awolowo University, Ile-Ife, Nigeria. The original version was administered on 10 patients with mild to moderate hypertension who were not part of the main study. After a week, the new English version was re-administered on the same participants. Responses from the original and new version were subjected to test-retest reliability using Spearman rank correlation coefficient. A testretest reliability value of $r=0.72$ was obtained. The questionnaire was self-administered and was collected immediately after completion. However, participants who were not literate in English language were assisted by a research assistant who helped to read (Yoruba version of DASI) loud to the hearing of the participant before completing the questionnaire.

Submaximal walk test: Each participant underwent a six-minute treadmill walk (6-MWT); a submaximal walk test which was conducted on a motorized treadmill. Instructions regarding the goal of the 6-MWT during treadmill walk test was adopted from the study of Stevens, et al. [22]. Prior to the 6-MTW, participant was instructed on how to increase and decrease the speed of the treadmill along with how to stop and restart the treadmill if needed to rest. The standard encouragement such as "you are doing fine", keep it up" was given at 2 and 4-minutes intervals. The initial speed of the treadmill walk was set at 1 mile per hour $(3.3 \mathrm{~km} / \mathrm{h})$ and the minimal speed was 0.6 miles per hour $(1.2 \mathrm{~km} / \mathrm{h})$ without any inclination ( $0 \%$ elevation). Exercise intensity was monitored using the polar heart rate monitor not exceeding $60-70 \%$ of maximal heart rate (MHR). The treadmill's data panel showing speed and distance traveled was not visible to the participant for the period of 6 minutes. However, only the start, stop, and speed up or slow down buttons were accessible to the participant [22]. In addition, total rest time and the Borg dyspnea scale were recorded. The total distance covered was recorded by a rolling measure device attached directly to the treadmill. Post-exercise heart rate, systolic and diastolic blood pressures were taken again during the recovery time. Estimated $\mathrm{VO}_{2}$ max during 6-TMW was derived from the predictive equation;

Computation: $\mathrm{VO}_{2}$ max (maximal oxygen consumption $)=$ walking distance $/ 6 \mathrm{~min} \times 0.1+3.5(\mathrm{~mL} /$ $\mathrm{kg} / \mathrm{min}$ ) [23].

Data analyses: Data obtained were summarized using descriptive statistics of frequency, percentage, 
Table 1: Distribution of socio-demographic characteristics of participants.

\begin{tabular}{|c|c|c|}
\hline Variable & $\mathbf{n}$ & $\%$ \\
\hline \multicolumn{3}{|c|}{ Age group (years) } \\
\hline $40-50$ & 35 & 23.3 \\
\hline $50-60$ & 48 & 32.0 \\
\hline$>60$ & 67 & 44.7 \\
\hline \multicolumn{3}{|l|}{ Gender } \\
\hline Male & 54 & 36.0 \\
\hline Female & 96 & 64.0 \\
\hline \multicolumn{3}{|l|}{ Occupation } \\
\hline Artisan/farmer & 32 & 21.3 \\
\hline Business & 34 & 22.7 \\
\hline Civil servant & 36 & 24.0 \\
\hline Retiree & 48 & 32.0 \\
\hline \multicolumn{3}{|l|}{ Educational level } \\
\hline Primary & 26 & 17.3 \\
\hline Secondary & 45 & 30.0 \\
\hline Post-secondary & 79 & 52.7 \\
\hline \multicolumn{3}{|l|}{ Monthly income } \\
\hline$<100,000$ & 72 & 48.0 \\
\hline $100,000-200,00$ & 44 & 29.3 \\
\hline$>200,000$ & 34 & 22.7 \\
\hline \multicolumn{3}{|c|}{ Onset of hypertension } \\
\hline$<5$ years & 92 & 61.3 \\
\hline$>5$ years & 58 & 38.7 \\
\hline \multicolumn{3}{|c|}{$\begin{array}{l}\text { Antihypertensive } \\
\text { medication prescribed }^{\dagger}\end{array}$} \\
\hline ACE-I & 58 & 38.6 \\
\hline ARB & 46 & 30.6 \\
\hline ASA & 84 & 56.0 \\
\hline CCB & 48 & 32.0 \\
\hline DIU & 78 & 52.0 \\
\hline BB & 42 & 28.0 \\
\hline
\end{tabular}

ACE-I: Angiotensin Converting Enzyme Inhibitor; ARB: Angiotensin Receptor Blocker; ASA: Aspirin; CCB: Calcium Channel Blocker; DIU: Diuretics; BB: Beta Blocker; ${ }^{\dagger}$ Summation in percentage is greater than $100 \%$ due to combination of prescribed antihypertensive medications.

mean and standard deviation. Inferential statistics of independent t-test was used to compare male and female participants while paired t-test was used to assess the pre and post cardiovascular response to submaximal walk test, maximum oxygen consumption, exertion level. One-way ANOVA and LSD post - hoc analysis was used to determine point of significant difference in cardiovascular response (systolic blood pressure, diastolic blood pressure, heart rate, and rate pressure product) during 6-MTW between male and female participants. Pearson productmoment correlation analysis was used to determine the relationship between selected anthropometric variables, cardiovascular parameters and the two dependent variables [estimated $\mathrm{DASI} \mathrm{VO}_{2} \max$ and 6-MTW $\mathrm{VO}_{2}$ max].

\section{Results}

A total of 150 hypertensive patients comprising 54 males and 96 females participated in the study (Table 1 ). The mean age of participants was $52.0 \pm 6.8$ years. They were comparable in all physical characteristics except the body mass index (BMI) $(p<0.05)$. The means of heart rate $(H R)$, systolic and diastolic blood pressure (SBP and DBP) and RPP were $71.5 \pm 13.7$ ) beat/min, $127.4 \pm 18.6) \mathrm{mmHg}, 82.3 \pm 9.3 \mathrm{mmHg}$ and $9.1 \pm 1.9$ $\left(\times 10^{3}\right)$ respectively. There was no significant difference in all cardiovascular parameters between male and female participants except HR ( $<<0.05)$ (Table 2). Table 3 showed the results of functional capacity assessed by DASI ( $\left.\mathrm{VO}_{2} \max \right)$ and 6-MTW ( $\mathrm{VO}_{2}$ max). The means of estimated $\mathrm{VO}_{2}$ max for DASI and 6-MTW were $24.4 \pm$ 5.7 and $12.5 \pm 3.6) \mathrm{mL} / \mathrm{kg} / \mathrm{min}$ respectively. There was no significant difference in functional capacity between male and female participants as measured by DASI $(\mathrm{t}=0.872 ; \mathrm{p}=0.388$ ). However, there was significant difference in functional capacity between male and female participants assessed by 6-MTW $(t=2.105 ; p=$ 0.041). The rate of perceived exertion during 6-MTW was not significantly different between male and female participants $(t=-1.126 ; p=0.266)$.

Table 4 showed cardiovascular response of the participants to submaximal walk test. There were significant changes between pre and post SBP $(\mathrm{t}=$ 3.171; $\mathrm{p}=0.003), \mathrm{HR}(\mathrm{t}=8.633 ; \mathrm{t}=0.001)$ and RPP $(\mathrm{t}$ $=8.566 ; p=0.001)$. Furthermore, Table 5 showed oneaway ANOVA comparison of pre and post cardiovascular response to submaximal walk test between male and female participants. The results showed that there were significant changes in HR (F-ratio $=23.168 ; p=0.001$ ) and RPP (F-ratio $=18.837 ; p=0.001$ ). Table 6 showed the relationship between selected anthropometric variables, DASI and 6-MTW. The results showed that there were significant inverse correlations between age and DASI $(r=-0.34 ; p=0.006)$ and 6-MTW ( $r=-0.39$; $p=0.005)$. Similarly, there were significant inverse correlations between body mass index and DASI ( $r$ $=-0.40 ; p=0.012)$ and 6-MTW $(r=-0.31 ; p=0.043)$. Furthermore, there was significant correlation between estimated $\mathrm{VO}_{2}$ max assessed by DASI and 6-MTW ( $r=$ $0.58 ; p=0.001$ ).

\section{Discussion}

This study investigated the functional capacity of patients with hypertension using the self-reported daily tool; Duke Activity Status Index (DASI) and correlated its outcomes with the results obtained from six-minute treadmill walk (6-MTW). Findings from our study showed that there was a significant inverse correlation between estimated DASI's $\mathrm{VO}_{2}$ max and some physical characteristics including age 
Table 2: Comparison of the physical characteristics and cardiovascular parameters of male and female participants.

\begin{tabular}{|c|c|c|c|c|c|}
\hline Variable & $\begin{array}{l}\text { All } \\
(\mathrm{N}=150) \\
\text { Mean } \pm \text { SD }\end{array}$ & $\begin{array}{l}\text { Male } \\
(n=54) \\
\text { Mean } \pm \text { SD }\end{array}$ & $\begin{array}{l}\text { Female } \\
(n=96) \\
\text { Mean } \pm \text { SD }\end{array}$ & t - cal. & $p$-value \\
\hline Age (years) & $52.0 \pm 6.8$ & $52.6 \pm 8.13$ & $51.8 \pm 6.0$ & 0.399 & 0.692 \\
\hline Weight (kg) & $80.1 \pm 14.9$ & $75.9 \pm 15.60$ & $82.5 \pm 14.3$ & -1.524 & 0.134 \\
\hline BMI $\left(\mathrm{kg} / \mathrm{m}^{2}\right)$ & $29.7 \pm 6.5$ & $26.0 \pm 4.19$ & $31.8 \pm 6.7$ & -3.319 & $0.002^{*}$ \\
\hline $\mathrm{SBP}(\mathrm{mmHg})$ & $127.4 \pm 18.6$ & $128.0 \pm 17.9$ & $127.3 \pm 19.2$ & 0.158 & 0.875 \\
\hline $\mathrm{DBP}(\mathrm{mmHg})$ & $82.3 \pm 9.3$ & $81.8 \pm 10.56$ & $82.6 \pm 8.7$ & 0.283 & 0.778 \\
\hline HR (beat/min) & $71.5 \pm 13.2$ & $77.6 \pm 9.01$ & $68.1 \pm 14.0$ & 2.585 & $0.013^{*}$ \\
\hline $\operatorname{RPP}\left(\times 10^{3}\right)$ & $9.1 \pm 1.9$ & $9.9 \pm 1.9$ & $8.6 \pm 1.9$ & 2.371 & 0.817 \\
\hline
\end{tabular}

"p < 0.05; BMI: Body Mass Index; SBP: Systolic Blood Pressure; DBP: Diastolic Blood Pressure; HR: Heart Rate; RPP: Rate Pressure Product

Table 3: Comparison of functional capacity measures and exertion level between male and female participants.

\begin{tabular}{|c|c|c|c|c|c|}
\hline Variable & $\begin{array}{l}\text { All } \\
(\mathrm{N}=150) \\
\text { Mean } \pm \text { SD }\end{array}$ & $\begin{array}{l}\text { Male } \\
(n=54) \\
\text { Mean } \pm \text { SD }\end{array}$ & $\begin{array}{l}\text { Female } \\
(n=96) \\
\text { Mean } \pm \text { SD }\end{array}$ & t-cal. & p-value \\
\hline DASI $\left(\mathrm{VO}_{2} \mathrm{max}\right) \mathrm{mL} / \mathrm{kg} / \mathrm{min}$ & $24.4 \pm 5.7$ & $25.4 \pm 4.4$ & $23.9 \pm 6.3$ & 0.872 & 0.388 \\
\hline DASI (METs) & $7.0 \pm 1.6$ & $7.3 \pm 1.3$ & $6.8 \pm 1.8$ & 0.872 & 0.388 \\
\hline 6-MTW $\left(\mathrm{VO}_{2} \max \right) \mathrm{mL} / \mathrm{kg} / \mathrm{min}$ & $12.6 \pm 3.6$ & $12.4 \pm 3.4$ & $10.6 \pm 2.3$ & 2.105 & $0.041^{*}$ \\
\hline 6-MTW (METs) & $3.6 \pm 1.1$ & $3.6 \pm 1.0$ & $2.9 \pm 0.7$ & 2.105 & $0.041^{*}$ \\
\hline Exertion level & $3.3 \pm 1.1$ & $3.1 \pm 0.8$ & $3.5 \pm 1.2$ & -1.126 & 0.266 \\
\hline
\end{tabular}

DASI: Duke Activity Status Index; METs: Metabolic Equivalents; 6-MTW: 6-Minute Treadmill Walk; $\mathrm{VO}_{2}$ max: Maximal Oxygen Consumption

Table 4: Cardiovascular response to 6 -minute treadmill walk $(n=150)$.

\begin{tabular}{|l|l|l|l|l|}
\hline Variable & Pre-6-MTW Mean \pm SD & Post-6-MTW Mean \pm SD & t - cal. & p-value \\
\hline SBP $(\mathrm{mmHg})$ & $133.9 \pm 20.0$ & $127.4 \pm 18.6$ & 3.171 & $0.003^{*}$ \\
\hline DBP $(\mathrm{mmHg})$ & $83.7 \pm 11.3$ & $82.3 \pm 9.32$ & 1.132 & 0.263 \\
\hline HR $($ beat $/ \mathrm{min})$ & $94.9 \pm 16.4$ & $71.5 \pm 13.17$ & 8.633 & $0.001^{*}$ \\
\hline RPP $\left(\times 10^{3}\right)$ & $12.7 \pm 2.9$ & $9.1 \pm 1.9$ & 8.566 & $0.001^{*}$ \\
\hline
\end{tabular}

${ }^{*} p<0.05$; 6-MTW: 6-Minute Treadmill Walk; SBP: Systolic Blood Pressure; DBP: Diastolic Blood Pressure; HR: Heart Rate; RPP: Rate Pressure Product

Table 5: Pre and post cardiovascular response to 6-minute treadmill walk between male and female participants.

\begin{tabular}{|c|c|c|c|c|c|c|}
\hline \multirow[b]{2}{*}{ Variable } & \multicolumn{2}{|c|}{$\begin{array}{c}\text { Male } \\
(n=54)\end{array}$} & \multicolumn{2}{|c|}{$\begin{array}{l}\text { Female } \\
(n=96)\end{array}$} & \multirow[b]{2}{*}{ F - ratio } & \multirow[b]{2}{*}{ p-value } \\
\hline & $\begin{array}{l}\text { Pre-6-MTW } \\
\text { Mean } \pm \text { SD }\end{array}$ & $\begin{array}{l}\text { Post-6-MTW } \\
\text { Mean } \pm \text { SD }\end{array}$ & $\begin{array}{l}\text { Pre-6-MTW } \\
\text { Mean } \pm \text { SD }\end{array}$ & $\begin{array}{l}\text { Post-6-MTW } \\
\text { Mean } \pm \text { SD }\end{array}$ & & \\
\hline $\mathrm{SBP}(\mathrm{mmHg})$ & $128.0 \pm 17.9$ & $128.6 \pm 19.2$ & $127.1 \pm 19.2$ & $130.9 \pm 20.2$ & 1.642 & 0.185 \\
\hline $\mathrm{DBP}(\mathrm{mmHg})$ & $81.8 \pm 10.6$ & $81.9 \pm 12.8$ & $82.6 \pm 8.7$ & $84.8 \pm 10.4$ & 0.483 & 0.695 \\
\hline HR (beat/min) & $77.6 \pm 9.1^{a}$ & $96.9 \pm 17.7^{b}$ & $68.1 \pm 14.0^{c}$ & $93.8 \pm 15.9^{d}$ & 23.168 & $0.001^{*}$ \\
\hline $\operatorname{RPP}\left(\times 10^{3}\right)$ & $9.9 \pm 1.9^{a}$ & $26.2 \pm 6.1^{b}$ & $8.6 \pm 1.9^{c}$ & $13.9 \pm 3.2^{d}$ & 18.837 & $0.001^{*}$ \\
\hline
\end{tabular}

" $\mathrm{p}<$ 0.05; 6-MTW: 6-Minute Treadmill Walk; SBP: Systolic blood pressure; DBP: Diastolic Blood Pressure; HR: Heart Rate; RPP: Rate Pressure Product; Superscripts $(a, b, c, d)$ for a particular variable, mode means with different superscript are significantly different $(p<0.05)$; Mode means with same superscripts are not significantly $(p>0.05)$ different when only one contrast is significant, one of the cell means has no superscript attached. The pair of cell means that is significant has different superscripts.

and body mass index (BMI). This is contrary to the findings of Satipati, et al. [24] who reported that age and $\mathrm{BMI}$ had direct relationship with $\mathrm{VO}_{2}$ max among young sedentary subjects. The plausible explanation for the difference might due to the type of study participants in our study compared to previous study. 
Table 6: Correlation between self-reported activity, submaximal walk test and selected anthropometric variables.

\begin{tabular}{|l|l|l|l|l|}
\hline \multirow{2}{*}{ Variable } & \multicolumn{2}{|c|}{ Self-reported Activity DASI } & \multicolumn{2}{c|}{ Sub-maximal Walk Test 6-MTW } \\
\hline Age $($ year) & p & p & r & p \\
\hline BMI $\left(\mathrm{Kg} / \mathrm{m}^{2}\right)$ & -0.39 & $0.006^{*}$ & -0.38 & $0.005^{*}$ \\
\hline DASI & -0.35 & $0.012^{*}$ & -0.29 & $0.043^{*}$ \\
\hline $6-M T W(m)$ & 1.00 & $0.001^{* *}$ & 0.58 & $0.001^{* *}$ \\
\hline $\begin{array}{l}V_{2} \text { max } \\
\mathrm{mL} / \mathrm{kg} / \text { min }\end{array}$ & 0.58 & $0.001^{* *}$ & 1.00 & $0.001^{* *}$ \\
\hline
\end{tabular}

${ }^{*}$ Correlation is significant at $p<0.05$ level (2-tailed); ${ }^{* *}$ Correlation is significant at $p<0.001$ level (2-tailed); BMI: Body Mass Index, DASI: Duke Activity Status Index, 6-MTW: 6-Minute Treadmill Walk

Our participants were middle aged patients with hypertension who were slightly overweight and obese. There is growing evidence that age and high BMI have direct relationship with etiological development of hypertension [25]. Similarly, hypertension has been reported to be linked with reduction in $\mathrm{VO}_{2} \max$ due to epithelial dysfunction. More importantly, most patients with hypertension usually engage in sedentary lifestyle and low physical fitness level with poor exercise tolerance. All these factors might be responsible for inverse relationship between $\mathrm{VO}_{2}$ max, age and BMI.

Findings from our study showed that there was no gender difference in the functional capacity between male and female participants as estimated by DASI. This is similar to the findings of a previous study reporting no gender difference in functional capacity between male and female subjects [17]. The reason why there was no gender difference might due to low activity of daily living involved DASI's assessment of $\mathrm{VO}_{2}$ max. However, we observed a significant difference during a six-minute treadmill walk (6-MTW) test between male and female. Although, 6-MTW is a submaximal walk test, differences in body weight and BMI between male and female could account for significant higher $\mathrm{VO}_{2}$ max in male. During the 6-MTW, findings from our study showed that there were significant differences in the pre and post exercise heart rate (HR), systolic blood pressure (SBP), and rate pressure product (RPP) among participants. This finding is in support of a previous study by Pescatello, et al. [26] who investigated the short-term effect of dynamic exercise on arterial blood pressure and concluded that dynamic exercise temporarily induces elevation of HR, SBP and RPP. Thereafter, a significant reduction in the cardiovascular parameters ensued during recovery stage. Furthermore, Nicholas, [27] also reported that the HR increases at onset of exercise training rapidly which was associated with normal cardiovascular functioning which has been identified as a powerful predictor of patient's prognosis during exercise rehabilitation. However, comparison of male and female participants' response to 6-MTW showed that there was no significant difference in the SBP and
DBP. This is in agreement with findings of some previous study that gender has no significant effect on response to dynamic exercise as both genders respond the same way to exercise regimen [28]. It has been observed that the integrated efforts and health of the pulmonary, cardiovascular, and skeletal muscle systems dictates an individual functional capacity [29].

The result of this study showed a statistically significant correlation between estimated DASI's $\mathrm{VO}_{2}$ max and that of 6-MTW. This is in agreement with a previous report that DASI is capable of measuring $\mathrm{VO}_{2}$ max accurately [30]. Hiltalky, [17] also reported that the DASI is a valid measure of $\mathrm{VO}_{2}$ max and estimates $\mathrm{VO}_{2}$ max based on individual ability to perform variety of common activities. In addition, Phillips, et al. [30] examined the clinical role of the DASI in selection of the optimal type of stress myocardial perfusion imaging study in patients with known or suspected ischemic heart disease. They concluded that the DASI was a useful pre-test tool to determine patients' ability to achieve appropriate metabolic equivalents (METs) and have the potential to guide selection of exercise treadmill versus pharmacological stress and ultimately improved laboratory efficiency. Previously, Alonso, et al. [31] had examined the reliability, validity and responsiveness to clinical change of the DASI in patients with cardiac challenges. They concluded that the DASI is reliable, valid and responsive to clinical changes in patients with chronic coronary disease. Furthermore, Leslee, et al. [32] reported the prognostic value of estimated functional capacity using the DASI's assessment among women with suspected myocardial ischemia. The finding showed that functional impairment estimated by the DASI correlated with indeterminate exercise test results associated with an adverse prognosis. Hence, functional capacity reflects the ability to perform activities of daily living that require sustained aerobic metabolism and oxygen utilization in different disease pathologies. It is noteworthy that easy and rapid application of DASI in the assessment of functional capacity is of clinical importance in busy clinical schedules in many hospitals especially in low and middle income countries. Findings from this study may help to limit problems with 
laboratory facilities and inadequate experts in the assessment of functional capacity in many patients with cardiac challenges.

\section{Conclusions}

In conclusion, the estimated functional capacity assessed by self-reported activity; the Duke Activity Status Index demonstrated significant positive correlation with submaximal walk test in patients with hypertension. Therefore, DASI may be an easy tool for assessing functional capacity of patients with comorbidities that limits walking ability or for quick assessment of functional capacity during busy clinical schedule among patients with hypertension.

\section{Limitations}

There are limitations in our study and findings from this study should be interpreted with caution. First, this study was a cross-sectional survey and causal inference cannot be made, thus limiting its generalizability to other patients with hypertension. Also, participants in ourstudy were patients with mild to moderate hypertension who were placed on different anti-hypertensive medications and perhaps might affect the outcome of this study. Furthermore, patients with severe hypertension might not present with similar results due to severity of the condition. More importantly, the overall physical activity level of these patients was not assessed prior to this study; hence, level of physical fitness may differ from one patient to the other. However, despite these limitations, comparison of our DASI $\mathrm{VO}_{2}$ max results with that of submaximal walk test showed significant correlation.

\section{Acknowledgements}

The authors wish to thank the Consortium for Advanced Research Training in Africa (CARTA) for providing technical support. CARTA is jointly led by the African Population and Health Research Center and the University of the Witwatersrand and funded by the Wellcome Trust (UK) (Grant No: 087547/Z/08/Z), the Department for International Development (DfID) under the Development Partnerships in Higher Education (DelPHE), the Carnegie Corporation of New York (Grant No: B 8606), the Ford Foundation (Grant No: 11000399), Swedish International Development Corporation Agency - SIDA (grant: 54100029), Google.Org (Grant No: 191994), and MacArthur Foundation (Grant No: 1095915-000-INP). We also wish to thank all participants for their time and cooperation.

\section{Disclosure of Interests}

The authors have no competing interests to declare.

\section{Ethics}

Ethical approval was obtained from the Research and Ethics Committee of the OAUTHC, Ile - Ife, Nigeria.

\section{Funding}

This work was not funded.

\section{References}

1. Rapsomaniki E, Timmis A, George J, Pujades-Rodriguez M, Shah AD, et al. (2014) Blood pressure and incidence of twelve cardiovascular diseases: Lifetime risks, healthy life-years lost, and age-specific associations in 1.25 million people. Lancet 383: 1899-1911.

2. World Health Organization (2021) Cardiovascular diseases.

3. Isezuo SA, Sabir AA, Ohwovorilole AE, Fasanmade OA (2011) Prevalence, associated factors and relationship between pre hypertension and hypertension: A study of two ethnic African populations in Northern Nigeria. J Hum Hypertens 25: 224-230.

4. Familoni OB, Alebiosu CO, Odusan O, Raimi A (2003) Factors influencing target organ damage among hypertensive patients in Nigeria. Trop Cardiol 29: 21-24.

5. Centers for Disease Control and Prevention (2008) National Health and Nutrition Examination Survey, 2007-2008. National Center for Health Statistics.

6. American College of Sports Medicine (2007) Guidelines for exercise testing and prescription. ( $6^{\text {th }}$ edn), Lippincott Williams and Wilkins, Philadelphia.

7. Morrato EH, Hill JO, Wyatt HR, Ghushchyan V, Sullivan PW (2007) Physical activity in U.S. adults with diabetes and at risk for developing diabetes, 2003. Diabetes Care 30: 203-209.

8. Awotidebe TO, Adeyeye VO, Ogunyemi SA, Bisiriyu LA, Adedoyin RA, et al. (2017) Joint predictability of physical activity and bodyweight status on health-related quality of life of patients with hypertension. J Exerc Rehabil 13: 588598.

9. Arena R, Myers J, Williams MA, Gulati M, Kligfield P, et al. (2007) Assessment of functional capacity in clinical and research settings: A scientific statement from the American Heart Association Committee on Exercise, Rehabilitation, and Prevention of the Council on Clinical Cardiology and the Council on Cardiovascular Nursing. Circulation 116: 329-343.

10. Gappmaier E (2012) The submaximal clinical exercise tolerance test (SXTT) to establish safe exercise prescription parameters for patients with chronic disease and disability. Cardiopulm Phys Ther J 23: 19-29.

11. Adedoyin RA, Adeyanju SA, Balogun MO, Akintomide AO, Adebayo RA, et al. (2010) Assessment of exercise capacity in African patients with chronic heart failure using sixminutes walk test. Int J Gen Med 3: 109-113.

12. de Groot JF, Takken T (2011) The six-minute walk test in paediatric populations. J Physiother 57: 128.

13. Cooper CB (2001) Exercise in chronic pulmonary disease: Aerobic exercise prescription. Med Sci Sports Exerc 33: S671-S679.

14. Ibikunle AF, Adedoyin RA, Awotidebe TO, Fasakin OM, Okonji AM, et al. (2020) Validation of three-minute walk test for the assessment of functional capacity among patients with hypertension. J Clin Exp Cardiol 11: 662.

15. Awotidebe TO, Adeyeye VO, Adedoyin RA, Oke KI, Ativie $\mathrm{RN}$, et al. (2016) Assessment of functional capacity in patients with hypertension using the six-minute walk test. West Indian Med J. 
16. Shaw LJ, Olson MB, Kip K, Kelsey SF, Johnson BD, et al. (2006) The value of estimated functional capacity in estimating outcome: Results from the NHBLI-Sponsored Women's Ischemia Syndrome Evaluation (WISE) Study. J Am Coll Cardiol 47: S36-S43.

17. Hlatky MA, Boineau RE, Higginbotham MB, Lee KL, Mark DB, et al. (1987) A brief self-administered questionnaire to determine functional capacity (the Duke Activity Status Index). Am J Cardiol 64: 651-654.

18. Goldman L, Hashimoto B, Cook EF, Loscalzo A (1981) Comparative reproducibility and validity of systems for assessing cardiovascular functional class: Advantages of a new specific activity scale. Circulation 64: 1227-1234.

19. Gibbons WJ, Fruchter N, Sloan S, Levy RD (2001) Reference values for a multiple repetition 6-minute walk test in healthy adults older than 20 years. J Cardiopulm Rehabil 21: 87-93.

20. Kasiulevičius V, Šapoka V, Filipavičiūtè R (2006) Sample size calculation in epidemiological studies. Gerontologija 7: 225-231.

21. Ekwunife Ol, Aguwa CN (2011) A meta-analysis of prevalence rate of hypertension in Nigerian populations. $J$ Public Health Epidemiol 3: 604-607.

22. Stevens D, Elpern E, Sharma K, Szidon P, Ankin M, et al. (1999) Comparison of hallway and treadmill six-minute walk tests. Am J Respir Crit Care Med 160: 1540-1543.

23. American College of Sport Medicine (ACSM) (1995) Prediction of maximum oxygen consumption $\left(\mathrm{VO}_{2} \max \right)$ during level walking.

24. Chatterjee S, Chatterjee P, Bandyopadhyay A (2006) Prediction of maximal oxygen consumption from body mass, height and body surface area in young sedentary subjects. Indian J Physiol Pharmacol 50: 181-186.
25. Harris MM, Stevens J, Thomas N, Schreiner P, Folsom AR (2000) Association of fat distribution and obesity with hypertension in a bi-ethnic population: The ARIC study. Atherosclerosis risk in communities study. Obes Res 8: 516-524.

26. Pescatello LS, Fargo AE, Leach Jr CN, Scherzer HH (1991) Short-term effect of dynamic exercise on arterial blood pressure. Circulation 83: 1557-1561.

27. Leeper NJ, Dewey FE, Ashley EA, Sandri M, Tan SY, et al. (2007) Prognostic value of heart rate increase at onset of exercise testing. Circulation 115: 468-474.

28. Le VV, Mitiku T, Sungar G, Myers J, Froelicher V (2008) The blood pressure response to dynamic exercise testing: A systematic review. Prog Cardiovasc Dis 51: 135-160.

29. Arena R, Lavie CJ, Milani RV, Myers J, Guazzi M (2007) Cardiopulmonary exercise testing in patients with pulmonary arterial hypertension: An evidence-based review. J Heart Lung Transplant 29: 159-173.

30. Phillips L, Wang JW, Pfeffer B, Gianos E, Fisher D, et al. (2011) Clinical role of the Duke Activity Status Index in the selection of the optimal type of stress myocardial perfusion imaging study in patients with known or suspected ischemic heart disease. J Nucl Cardiol 18: 1015-1020.

31. Alonso J, Permanyer-Miralda G, Cascant P, Brotons C, Prieto L, et al. (1997) Measuring functional status of chronic coronary patients: Reliability, validity and responsiveness to clinical change of the reduced version of the Duke Activity Status Index (DASI). Eur Heart J 18: 414-419.

32. Leslee JS, Marian BO, Kevin K, Sheryl FK, Delia BJ, et al. (2006) The prognostic value of estimated functional capacity based on self-reported functional capacity by the DASI. J Am Coll Cardiol 47: 0735-1097. 